\title{
Reconsidering the peripheral in global health
}

\author{
Reconsiderações sobre o periférico na saúde global
}

\author{
João Nunes \\ Lecturer, International Relations/University of York. \\ Heslington - York - United Kingdom \\ joao.nunes@york.ac.uk
}

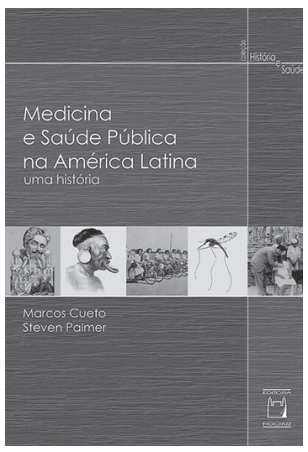

CUETO, Marcos; PALMER, Steven. Medicina e saúde pública na América Latina: uma história. Tradução Sérgio Lamarão. Rio de Janeiro: Editora Fiocruz. 2016. 364p.
$\mathrm{M}$

arcos Cueto and Steven Palmer have written an ambitious history of medicine and public health in Latin America that not only repositions this region in the global context, but also brings new insights into some of the most pressing contemporary debates in global health. This review considers some key contributions of this book, which overall question commonly held assumptions about the origins and trajectory of international and global health - pertaining most notably to the role of countries and regions normally deemed "marginal" or "peripheral."

The foundation upon which these contributions rest is Cueto and Palmer's detailed account of the unique character of Latin American medicine and public health. The authors emphasize the pluralism of the region's medical scenario, which resulted from complex exchanges that went beyond the top-down imposition of a university-based orthodoxy. Instead, the book recognizes the interaction of multiple forms of medical and religious knowledge, whose elements and practices populations resorted to (and often combined). In practice, pluralism meant the coexistence of European, African, indigenous and, later, North American practices, as well as of popular and Western biomedical knowledge, so that the region became "a dynamic border between Western and non-Western medicine" (Cueto, Palmer, 2016, p.70). Here, the book interestingly argues that despite its homogeneizing tendencies, the growth of public health under the auspices of the modern nation-state did not lead to the erasure of popular and alternative medical practices. Rather, biomedical hegemony and popular medical "dissent" (p.119) coexisted quite peacefully. The authors suggest, for example, that healing cultures like santería and candomblé emerged, were consolidated, and expanded, within the structures of nationalism, urbanization, sanitarism, and medical research. The hegemony of doctors, in other words, paved the way for the interstitial presence of a diverse range of healers and priests. The account of this long process 
of "medical miscegenation" (mestiçagem médica, p.28), from the colonial period to the end of the twentieth century and beyond, is one of the main contributions of this book.

Cueto and Palmer also break new ground by starting from this account of pluralism to reconsider the role of Latin America in the construction of "Western medicine." Instead of assuming that medical knowledge flowed in a unidirectional manner, the authors emphasize the "polycentric networks" and the "creative interaction" (p.16-17) between the metropolis and the colony. They analyze the contribution of medical tropicalistas, who decisively advanced not only the subfield of tropical medicine, but also Western medicine more generally. The book shows, for example, how Latin American researchers pushed beyond miasmatic theories of disease, challenging them from the standpoint of contagionism and germ theory. Rather than Latin America being a mere laboratory where Western ideas were tested and validated, Cueto and Palmer show the "peripheral precedence" (p.63) of practices that have since become part of the canon of Western medicine.

This leads to another contribution of this book: the manner in which it shows Latin America to be at the forefront of the creation and development of international and global health. The role of Latin America in this regard stems from the fact that during the twentieth century, by falling within the imperial reach of the USA, this region became a site for international health interventions under US hegemony. As a result of this, it became an arena for international health innovation, contributing decisively for the subsequent design of the post-WWII international health system.

Crucially, however, Cueto and Palmer emphasize that throughout this process Latin America was far from being a passive recipient of international health efforts. Here, the book eloquently speaks to an emerging literature that questions Western-centric accounts of global health, which often relegate countries and regions in the Global South to a subaltern position in which they are constantly being acted upon by outsiders. Providing a much-needed "view from the South," the book highlights the agency of Latin America. This agency - albeit constrained and dependent upon international structures - was visible for example in the complex ways in which colonial medicine was taken up by local populations. It is also present in the appropriation of international health interventions to serve local interests and agendas. As the authors note, medical actors and institutions in Latin America were decisive in managing and implementing international health efforts, sometimes channeling these efforts to question existing power structures. One example is the way in which the resources and reputation of the Rockefeller Foundation were mobilized by local actors in the service of their own progressive public health agendas - in issues like rural health, occupational health, or the health of women and children. It thus becomes difficult to sustain that US models of biomedicine and public health were imposed upon Latin America. Rather, for Cueto and Palmer, one should recognize the presence of a "creative, reciprocally defining compromise between a variety of actors" (p.124) including state and non-state actors, both local to Latin America and in the US. The book reveals the rich texture of the political terrain in which international interventions were interpreted, incorporated, adapted, and resisted by Latin American actors. Their argument reclaims political dynamics that have long been absent from accounts of regional and global health. 
Overall, this book brings Latin America back to its rightful place in global health, positioning the region at the forefront of international medical and public health development. It also shows Latin America to be a site where contemporary tensions in global health are still being played out. One example is the clash between what the authors term the "survival culture" (p.15) and the "health in adversity" model (p.293). The former emphasizes a public health model focused on short-term fixes, while the latter seeks to mobilize health work as a mechanism of social integration aimed at reducing inequalities. The tension between the technical and social views of public health is not unique to Latin America. Nonetheless, Cueto and Palmer's analysis suggests that given the historical trajectory of global health and its indebtedness to developments in this part of the world, it is likely that Latin America will continue to provide valuable innovations and lessons. In addition to being an important and often overlooked - agent in the history of global health, Latin America is a fundamental site in which its future is being defined, negotiated, and struggled for.

\section{REFERENCE}

CUETO, Marcos; PALMER, Steven.

Medicina e saúde pública na América Latina: uma história. Tradução Sérgio Lamarão. Rio de Janeiro: Editora Fiocruz. 2016. 